\title{
Altered Expression of Mitoferrin and Frataxin, Larger Labile Iron Pool and Greater Mitochondrial DNA Damage in the Skeletal Muscle of Older Adults
}

\author{
Anna Picca ${ }^{1,2}{ }^{\circ}$, Sunil K. Saini ${ }^{3}{ }^{\oplus}$, Robert T. Mankowski ${ }^{3}$, George Kamenov ${ }^{4}(\mathbb{D}$, \\ Stephen D. Anton ${ }^{3}$, Todd M. Manini ${ }^{3}$, Thomas W. Buford ${ }^{5}$, Stephanie E. Wohlgemuth ${ }^{3}$, \\ Rui Xiao ${ }^{3} \mathbb{D}$, Riccardo Calvani ${ }^{1,2}$, Hélio José Coelho-Júnior ${ }^{6} \mathbb{D}$, Francesco Landi ${ }^{1,6}$, \\ Roberto Bernabei ${ }^{1,6}$, David A. Hood ${ }^{7}$, Emanuele Marzetti ${ }^{1,6, *}$ and Christiaan Leeuwenburgh ${ }^{3}$ \\ 1 Fondazione Policlinico Universitario “Agostino Gemelli" IRCCS, 00168 Rome, Italy; \\ anna.picca@guest.policlinicogemelli.it (A.P.); riccardo.calvani@guest.policlinicogemelli.it (R.C.); \\ francesco.landi@unicatt.it (F.L.); roberto.bernabei@unicatt.it (R.B.) \\ 2 Aging Research Center, Department of Neurobiology, Care Sciences and Society, \\ Karolinska Institutet and Stockholm University, SE-171 77 Stockholm, Sweden \\ 3 Department of Aging and Geriatric Research, Institute on Aging, University of Florida, Gainesville, FL 32611, \\ USA; sunil.saini@ufl.edu (S.K.S.); r.mankowski@ufl.edu (R.T.M.); santon@ufl.edu (S.D.A.); \\ tmanini@ufl.edu (T.M.M.); steffiw@ufl.edu (S.E.W.); rxiao@ufl.edu (R.X.); cleeuwen@ufl.edu (C.L.) \\ 4 Department of Geological Sciences, University of Florida, Gainesville, FL 32605, USA; kamenov@ufl.edu \\ 5 Department of Medicine, University of Alabama at Birmingham, Birmingham, AL 35205, USA; \\ twbuford@uabmc.edu \\ 6 Institute of Internal Medicine and Geriatrics, Università Cattolica del Sacro Cuore, 00168 Rome, Italy; \\ coelhojunior@hotmail.com.br \\ 7 Muscle Health Research Centre, School of Kinesiology and Health Science, York University, Toronto, \\ ON M3J 1P3, Canada; dhood@yorku.ca \\ * Correspondence: emanuele.marzetti@policlinicogemelli.it; Tel.: +39-(06)-3015-5559; Fax: +39-(06)-3051-911
}

Received: 18 November 2020; Accepted: 30 November 2020; Published: 2 December 2020

\begin{abstract}
Mitochondrial dysfunction and iron $(\mathrm{Fe})$ dyshomeostasis are invoked among the mechanisms contributing to muscle aging, possibly via a detrimental mitochondrial-iron feed-forward loop. We quantified the labile Fe pool, Fe isotopes, and the expression of mitochondrial Fe handling proteins in muscle biopsies obtained from young and older adults. The expression of key proteins of mitochondrial quality control (MQC) and the abundance of the mitochondrial DNA common deletion (mtDNA ${ }^{4977}$ ) were also assessed. An inverse association was found between total $\mathrm{Fe}$ and the heavier Fe isotope $\left({ }^{56} \mathrm{Fe}\right)$, indicating an increase in labile Fe abundance in cells with greater Fe content. The highest levels of labile Fe were detected in old participants with a Short Physical Performance Battery (SPPB) score $\leq 7$ (low-functioning, LF). Protein levels of mitoferrin and frataxin were, respectively, higher and lower in the LF group relative to young participants and older adults with SPPB scores $\geq 11$ (high-functioning, $\mathrm{HF}$ ). The mtDNA ${ }^{4977}$ relative abundance was greater in old than in young participants, regardless of SPPB category. Higher protein levels of Pink1 were detected in LF participants compared with young and HF groups. Finally, the ratio between lipidated and non-lipidated microtubule-associated protein 1A/1B-light chain 3 (i.e., LC3B II/I), as well as p62 protein expression was lower in old participants regardless of SPPB scores. Our findings indicate that cellular and mitochondrial Fe homeostasis is perturbed in the aged muscle (especially in LF older adults), as reflected by altered levels of mitoferrin and frataxin, which, together with MQC derangements, might contribute to loss of mtDNA stability.
\end{abstract}

Keywords: autophagy; iron dyshomeostasis; iron metabolism; iron isotopes; mitochondria; mitochondrial quality control; mitophagy; muscle aging; oxidative stress; physical performance 


\section{Introduction}

The preservation of mobility and functional independence in older adults has become a clinical and public health priority, as well as a major goal of the National Institute on Aging and the National Institutes of Health strategic plan for research on aging [1]. Our work and that of others have shown that low-functioning (LF) older adults have a more rapid functional decline compared with those who are high-functioning (HF) [2-7]. Habitual walking speed and performance on standard measures of physical function can be considered a composite measure of healthy aging and predict mobility disability and all-cause mortality [3-7]. However, the biological mechanisms underlying the accelerated functional loss in LF older adults remain poorly understood, and few strategies are currently available to prevent this decline.

Mitochondrial dysfunction in skeletal muscle is invoked as a major factor underlying the onset and progression of functional decline during aging [8-11]. Yet, the molecular determinants underlying mitochondrial dysfunction in muscle and the associated functional decline are presently unclear. Notwithstanding, alterations in mitochondrial iron ( $\mathrm{Fe}$ ) handling in skeletal myocytes have been proposed as a mechanism leading to organelle dysfunction and muscle atrophy [12]. Indeed, variants in genes involved in the regulation of Fe handling were found to be associated with healthspan and physical performance in older adults $[13,14]$.

The majority of body $\mathrm{Fe}$ is sequestered as heme Fe into functional biomolecules, including hemoglobin, myoglobin, cytochromes, and heme thiolates [15]. A smaller fraction of non-heme Fe exists as metallic ion serving as an enzyme cofactor or bound to cytosolic ferritin and hemosiderin to form Fe reserves [15]. Non-heme Fe is also an integral part of transferrin and is core to mitochondrial electron transport chain (ETC) complexes within Fe-sulfur clusters (ISCs) [16,17]. Of all non-heme Fe, approximately $5 \%$ exists as a chelatable Fe fraction and feeds a labile Fe pool. The biological relevance of this fraction resides in its chemistry involving ferrous $\left(\mathrm{Fe}^{2+}\right)$ and ferric $\left(\mathrm{Fe}^{3+}\right)$ ions. $\mathrm{Fe}^{2+}$ participates in Fenton reactions and produce highly reactive radicals, holding the potential of generating protein, lipid and nucleic acid oxidative adducts which are detrimental to the cell $[18,19]$. The reduction of $\mathrm{Fe}^{3+}$ to $\mathrm{Fe}^{2+}$ in the human body is accompanied by Fe isotope fractionation resulting in enrichment of the lighter isotope $\left({ }^{54} \mathrm{Fe}\right)$ in the reduced Fe fraction $[20,21]$. Therefore, the isotope composition of the cellular Fe pool may represent a "surrogate" indicator of the cell's redox status.

The redistribution of non-heme Fe across tissues is regulated by the defensin-like hormone hepcidin via binding and subsequent degradation of the Fe export protein ferroportin [22,23]. Cellular Fe import, instead, occurs via a transferrin receptor (TfR) and is highly responsive to intracellular Fe levels. The two mitochondrial proteins, mitoferrin and frataxin, also participate in intracellular Fe handling. Mitoferrin, which is located at the inner mitochondrial membrane, regulates mitochondrial Fe import, while frataxin is pivotal for mitochondrial Fe storage. Studies in preclinical models have established that frataxin is also involved in heme biosynthesis, ISC cluster assembly, and aconitase repair $[24,25]$. Frataxin deficiency in humans results in mitochondrial Fe overload and Friedreich's ataxia, a major inheritable neurodegenerative disorder [26].

The skeletal muscle is the major bodily reservoir of non-heme Fe. The latter accumulates in muscles with aging, which has been linked to oxidative damage to biomolecules and organelles, including mitochondria [27-31]. As such, age-related mitochondrial dysfunction and Fe dyshomeostasis are advocated among the biological mechanisms involved in the pathogenesis of sarcopenia [12]. The existence of a mitochondrial-Fe feed-forward loop in the aging muscle has been hypothesized. This loop would involve perturbations in cellular Fe transport leading to Fe accrual, oxidative damage to mitochondrial DNA (mtDNA) and ETC complexes, together impinging on mitochondrial function and eventually generating a vicious circle that promotes further Fe overload and oxidative stress [12,32-34].

In light of the vital functions of mitochondria, the maintenance of organellar structural and functional integrity is essential for cell's homeostasis and is ensured by an integrated network of pathways (i.e., mitochondrial dynamics, mitophagy, biogenesis, and proteostasis), collectively termed mitochondrial quality control (MQC) [35-37]. The MQC axis becomes impaired during aging, which is 
thought to trigger and amplify mitochondrial dysfunction [37,38]. As a result, pro-inflammatory routes may be triggered to dispose dysfunctional organelles [39-44].

In a recent work by our group, we provided an initial appraisal of the relationship between Fe imbalance, mitochondrial damage in muscle, and chronic inflammation in a cohort of older adults [32]. In that study, we observed that Fe import via TfR, a main Fe import protein, was markedly decreased in muscles of older people. Moreover, an association between Fe dyshomeostasis and systemic inflammation-i.e., higher circulating levels of hepcidin, interleukin 6, and C-reactive protein-emerged as a relevant factor possibly contributing to physical function impairment [32].

In subsequent work detailed in this manuscript, we further explored the relationship between Fe imbalance and mitochondrial dyshomeostasis in muscle biopsies obtained from the same cohort of individuals. Specifically, we sought to determine whether a differential distribution of Fe isotopes within the labile Fe pool and changes in the expression of proteins involved in mitochondrial $\mathrm{Fe}$ handling (i.e., mitoferrin and frataxin) and MQC in muscle would be associated with aging and declining physical performance.

\section{Materials and Methods}

\subsection{Participants}

Physically inactive community-dwelling men and women aged 70 years and older or between the ages of 18 and 35 years were included in the study. The Recruitment Core of the University of Florida Claude D. Pepper Older Americans Independence Center coordinated participants enrolment, as previously described $[11,45,46]$. A set of eligibility criteria, common for the two age groups, was chosen to minimize the possible confounding effect of comorbidities, medications, and lifestyle habits on the relationship among physical performance, Fe metabolism, and measures of muscle mitochondrial quality, as detailed elsewhere [32,47].

Older adults were categorized in HF and LF according to the summary score obtained on the Short Physical Performance Battery (SPPB) [48]. In particular, participants with an SPPB score $\geq 11$ were classified as HF, while those who scored $\leq 7$ were categorized as LF. The cut-off values were chosen for their ability to predict relevant health outcomes in older adults (e.g., functional limitations, institutionalization, mortality) [48-52]. To allow greater discrimination in physical function and biochemical parameters between the two groups, participants scoring 8-10 on the SPPB were not included.

The study protocol was approved by the University of Florida's Institutional Review Board (IRB201300790) and all participants provided written informed consent prior to enrolment.

\subsection{Collection of Muscle Biopsies}

Muscle biopsies were obtained from the vastus lateralis of the dominant leg by percutaneous needle biopsy, under local anesthesia [46]. Upon collection, muscle specimens were cleaned of any visible blood and fat, snap-frozen in liquid nitrogen and stored at $-80{ }^{\circ} \mathrm{C}$ until further processing and analysis.

\subsection{Measurement of Iron Isotopes in Muscle Biopsies by Inductively Coupled Plasma-Mass Spectrometry}

All reagents used for the sample preparation and Fe ion-exchange purification were Optima-grade and the work was performed under Clean Lab (class 1000) environment. Between $0.013 \mathrm{~g}$ and $0.029 \mathrm{~g}$ of muscle tissue were digested for the determination of Fe concentration, following methods described elsewhere [32]. Briefly, tissues were digested in concentrated nitric acid $\left(\mathrm{HNO}_{3}\right)$ and $30 \%$ hydrogen peroxide $\left(\mathrm{H}_{2} \mathrm{O}_{2}\right)$ in pre-cleaned Teflon vials. A small fraction of the final solution was used for the determination of Fe concentration in muscle samples [32]. The remaining digested muscle solution was evaporated to dryness and converted to chlorides by $3 \times$ evaporation with $7 \mathrm{~N}$ hydrochloric acid (HCl). Fe was purified on an AG ${ }^{\circledR}$ MP-1M resin (Bio-Rad Laboratories, Hercules, CA, USA) following 
methods described by Maréchal et al. [53]. Ion-exchange columns were packed with $2 \mathrm{~mL}$ of $\mathrm{AG}^{\circledR}$ MP-1M (100-200 mesh) resin. After packing, the columns were washed with $0.5 \mathrm{~N} \mathrm{HNO}_{3}$, followed by milliQ water, then $1 \mathrm{~N} \mathrm{HCl}$ again followed by milliQ water. After the washing steps, the columns were equilibrated with $4 \mathrm{~mL} 7 \mathrm{~N} \mathrm{HCl}$. Samples were loaded in $7 \mathrm{~N} \mathrm{HCl}$ with $0.001 \% \mathrm{H}_{2} \mathrm{O}_{2}$. The matrix was eluted with $23 \mathrm{~mL}$ of $7 \mathrm{~N} \mathrm{HCl}$ and Fe was collected in $10 \mathrm{~mL} 1 \mathrm{~N} \mathrm{HCl}$. The Fe fraction was evaporated to dryness. After evaporation, $0.5 \mathrm{~mL}$ of $8 \mathrm{~N} \mathrm{HNO}_{3}$ were added to the dry residue and evaporated again. The samples were subsequently dissolved in $2 \% \mathrm{HNO}_{3}$ for Fe isotope measurements. The Fe yield after column purification was $101 \%( \pm 3 \%)$. Fe isotope measurements were performed on a Nu-Plasma 3 MC-ICP-MS (AMETEK, Wrexham, UK) in the high-resolution mode. Due to the low total Fe available, samples were introduced in the MC-ICP-MS via an Aridus3 desolvating nebulizer system (Teledyne CETAC, Omaha, NE, USA). All samples and standards were adjusted to $500 \mathrm{ppb}$ Fe in the final solution, which resulted in around $6.5 \mathrm{~V}$ signal for ${ }^{56} \mathrm{Fe}$. Fe isotope measurements were performed on Faraday detectors in standard-sample-standard mode with IRM014 used as the bracketing standard. Fe isotope data are presented in delta-notation $(\delta)$ in parts per thousand $(\%$ o) using the following equation [20]:

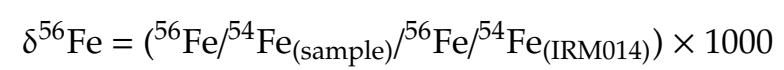

$\delta^{57} \mathrm{Fe}$ was calculated with Equation (1) using ${ }^{57} \mathrm{Fe} /{ }^{54} \mathrm{Fe}$ ratio instead of ${ }^{56} \mathrm{Fe} /{ }^{54} \mathrm{Fe}$. Fe isotopes measured in BCR2 standard $(n=7)$, prepared and analyzed together with the samples, yielded the following results: $\delta^{56} \mathrm{Fe}=0.097( \pm 0.014)$ and $\delta^{57} \mathrm{Fe}=0.163( \pm 0.048)$. These values are within the error of published data for BCR2 by Craddock and Dauphas [54]: $\delta^{56} \mathrm{Fe}=0.091( \pm 0.011)$ and $\delta^{57} \mathrm{Fe}=0.126( \pm 0.017)$.

\subsection{Western Immunoblotting}

Protein lysates were prepared from muscle biopsies and levels of beclin, microtubule-associated protein 1A/1B-light chain 3 (LC3B) I and II, frataxin, mitoferrin, sequestosome 1 (SQSTM1)/p62, Parkin, and phosphatase and tensin homolog-induced kinase 1 (Pink1) were measured by Western immunoblotting, as previously described [11]. A total of $50 \mu \mathrm{g}$ of protein was separated on $4-20 \%$ polyacrylamide gels (Bio-Rad Laboratories), transferred onto polyvinylidene difluoride membranes (Bio-Rad Laboratories), and blocked for $1 \mathrm{~h}$ in $2.5 \%$ or $5 \%$ milk in Tris-buffered saline with Tween 20 (Bio-Rad Laboratories), as appropriate (Table 1). Bovine serum albumin- and milk-blocked blots were probed with commercially available primary and secondary antibodies listed in Table 1 . Protein bands were detected with SuperSignal West Femto Maximum Sensitivity Substrate (Thermo Fisher Scientific, Waltham, MA, USA) using a ChemiDoc XRS imager (Bio-Rad Laboratories) and target bands were quantified using the Image Lab 6.0 software (Bio-Rad Laboratories). The "Total Lane Protein" setting was used for the quantification of target proteins. The spot density of each band was normalized to the total protein amount loaded in the same lane, as determined by the densitometric analysis of the corresponding Ponceau S-stained membranes $[55,56]$. 
Table 1. Technical specifications of the primary antibodies used for Western immunoblotting.

\begin{tabular}{ccccccc}
\hline Antibody & $\begin{array}{c}\text { Manufacturer and } \\
\text { Catalog Number }\end{array}$ & Type & Species & Dilution & Blocking & $\begin{array}{c}\text { Detected Band } \\
\text { MW (kDa) }\end{array}$ \\
\hline Beclin & $\begin{array}{c}\text { Cell Signaling } \\
\text { Technology (Beverly, } \\
\text { MA, USA) (\#3738S) }\end{array}$ & Polyclonal & Rabbit & $1: 2000$ & $\begin{array}{c}5 \% \text { BSA } \\
\text { TBS-t }\end{array}$ & 60 \\
\hline Frataxin & $\begin{array}{c}\text { Abcam (Cambridge, } \\
\text { MA, USA) (ab110328) }\end{array}$ & Monoclonal & Mouse & $1: 500$ & $\begin{array}{c}5 \% \text { milk } \\
\text { TBS-t }\end{array}$ & 23 \\
\hline LC3B & $\begin{array}{c}\text { Cell Signaling } \\
\text { Technology (\#2775S) }\end{array}$ & Polyclonal & Rabbit & $1: 1000$ & $\begin{array}{c}5 \% \text { BSA } \\
\text { TBS-t }\end{array}$ & 14 (LC3B II) \\
\hline Mitoferrin & Abcam (ab102959) & Polyclonal & Rabbit & $1: 1000$ & $\begin{array}{c}5 \% \text { milk } \\
\text { TBS-t }\end{array}$ & 37 \\
\hline SQSTM1/p62 & $\begin{array}{c}\text { Cell Signaling } \\
\text { Technology (\#5114S) }\end{array}$ & Polyclonal & Rabbit & $1: 2000$ & $\begin{array}{c}5 \% \text { BSA } \\
\text { TBS-t }\end{array}$ & 62 \\
\hline Parkin & Abcam (ab77924) & Monoclonal & Mouse & $2 \mu \mathrm{g} / \mathrm{mL}$ & $\begin{array}{c}2.5 \% \text { milk } \\
\text { TBS-t }\end{array}$ & 52 \\
\hline Pink1 & Abcam (ab23707) & Polyclonal & Rabbit & $1: 1000$ & $\begin{array}{c}5 \% \text { milk } \\
\text { TBS-t }\end{array}$ & 66 \\
\hline
\end{tabular}

Abbreviations: BSA, bovine serum abumin; LC3B, microtubule-associated protein 1A/1B-light chain 3; Pink1, phosphatase and tensin homolog-induced kinase 1; SQSTM1/p62, sequestosome 1/p62; TBS-t, Tris-buffered saline with Tween 20.

\subsection{Quantification of Mitochondrial DNA Deletion}

Quantitative real-time polymerase chain reaction (qRT-PCR) was used to determine muscle levels of the mtDNA common deletion of $4977 \mathrm{bp}\left(\mathrm{mtDNA}^{4977}\right)$ in total DNA purified as described elsewhere [57-62]. DNA purification was performed using a Wizard Genomic DNA Purification Kit (Promega, Madison, WI, USA) according to the manufacturer's instructions. Briefly, $10-20 \mathrm{mg}$ of muscle tissue were homogenized in $1 \mathrm{~mL}$ of nuclei cell lysis solution with a hard tissue disposable probe (Omni international, Kennesaw, GA, USA) on a PowerGen 500 homogenator (Thermo Fisher Scientific). DNA quantification was performed on a NanoDrop 1000 spectrophotometer (Thermo Fisher Scientific) and nucleic acid integrity was verified by gel electrophoresis on $0.8 \%$ agarose gel in $1 \times$ TBE $(90 \mathrm{mM}$ Tris-borate $\mathrm{pH} 7.4,90 \mathrm{mM}$ boric acid, $2.5 \mathrm{mM}$ ethylenediaminetetraacetic acid). Forward and reverse primers for the assessment of mtDNA ${ }^{4977}$ were designed to span both ends of the deletion (forward 5'-CCTTACACTATTCCTCATCACC-3'; reverse 5'-TGTGGTCTTTGGAGTAGAAACC-3'; amplicon length: 127 bp) [62]. Primer pairs were checked for their specificity of binding to the mitochondrial genome by verifying the lack of cross-binding to nuclear-mtDNA sequences (numts) and by running melting curve analysis, non-template control reactions, and gel electrophoresis of PCR products. Glyceraldehyde 3-phosphate dehydrogenase (GAPDH) was used as an internal control (forward 5'-CAGAACATCATCCCTGCCTCTAC-3'; reverse 5'-TTGAAGTCAGAGGAGACCACCTG-3'; amplicon length 251 bp). Each sample was analyzed in triplicate in $20 \mu \mathrm{L}$ final volume. The reaction mixture consisted of $1 \times$ Terra qPCR Direct SYBR Premix (Takara Bio USA Inc., Mountain View, CA, USA), $0.2 \mu \mathrm{M}$ forward and reverse primers, and $10 \mathrm{ng}$ of total DNA template. The amplification proceeded for 40 cycles. Amplification reactions were run on a CFX96 Touch ${ }^{\mathrm{TM}}$ Real-Time PCR Detection System (Bio-Rad Laboratories). The abundance of the mtDNA $^{4977}$ deletion was calculated according to the Pfaffl mathematical model using the formula $\mathrm{R}=2^{\Delta \Delta \mathrm{Ct}}$ [63] and normalized to the relative mtDNA content. MtDNA relative quantification was obtained by RT-PCR using the Human Mitochondrial DNA Monitoring Primer Kit (Takara Bio USA). The primers amplified mitochondrial genes corresponding to the nicotinamide adenine dinucleotide reduced form (NADH) dehydrogenase subunits 1 and 5 (ND1, ND5) and nuclear genes corresponding to solute carrier organic anion transporter family, member 2b1 (SLCO2B1), and serpin family A member 1 (SERPINA1) [32]. Differences in threshold cycle values for the ND1/SLCO2B1 pair $(\Delta \mathrm{Ct} 1=\mathrm{Ct}$ for SLCO2B1 - Ct for ND1) and the ND5/SERPINA1 pair $(\Delta \mathrm{C} t 2=\mathrm{Ct}$ for SERPINA1 - Ct for ND5) were 
calculated, and the average of $2^{\Delta \mathrm{Ct}}$ for the values of $\Delta \mathrm{Ct} 1$ and $\Delta \mathrm{Ct} 2$ was used as a measure of relative mtDNA abundance.

\subsection{Statistical Analysis}

The normal distribution of data was verified via the Kolmogorov-Smirnov test. Normally distributed continuous variables were compared by one-way analysis of variance (ANOVA) followed by Tukey's post-hoc test when appropriate. Differences for non-normally distributed continuous data were assessed by the non-parametric tests Mann-Whitney U and Kruskal-Wallis H with Dunns' post-hoc test as appropriate. Differences in categorical variables among groups were determined via $\chi^{2}$ statistics. Relationships between variables were explored by linear regression analysis and the Pearson's test. All analyses were performed using the GraphPrism 5.03 software (GraphPad Software, Inc., San Diego, CA, USA), with statistical significance set at $p<0.05$.

\section{Results}

\subsection{Study Participants}

Thirty-four participants, 11 young (six men and five women; median age: 22 years; interquartile range: $21-28)$ and 23 older adults (14 men and nine women; median age: 80 years; interquartile range: 71-82) were included in the study. The main characteristics of study participants according to age and SPPB categories were previously reported [32] and are shown in Table 2. Sex distribution, body mass index, and the number of disease conditions and medications were comparable among groups. Age did not differ between the two subgroups of older adults. Consistent with the study protocol, HF participants had higher SPPB scores than LF older adults $(p=0.0002)$. Old participants showed a greater abundance of muscle total Fe levels independent of the SPPB score $(p=0.0256)$.

Table 2. Characteristics of study participants according to age groups and physical performance categories.

\begin{tabular}{|c|c|c|c|c|}
\hline \multirow[b]{2}{*}{ Characteristic } & \multirow[t]{2}{*}{ Young $(n=11)$} & \multicolumn{2}{|c|}{ Old $(n=23)$} & \multirow[b]{2}{*}{$p$ Value } \\
\hline & & HF $(n=16)$ & LF $(n=7)$ & \\
\hline Age (years), median (IQR) & $22(21-28)$ & $73(71-81) *$ & $80.0(80-83) *$ & $<0.0001^{\mathrm{a}}$ \\
\hline Sex (women), $n(\%)$ & $5(45.5)$ & $4(25.0)$ & $5(71.4)$ & $0.1076^{b}$ \\
\hline $\mathrm{BMI}\left(\mathrm{kg} / \mathrm{m}^{2}\right)$, mean $\pm \mathrm{SD}$ & $24.9 \pm 4.2$ & $27.7 \pm 3.6$ & $27.8 \pm 4.2$ & $0.1604^{\mathrm{c}}$ \\
\hline Total iron levels (ppm), median (IQR) & $36.3(32.9-58.8)$ & $76.8(54.0-111.3) *$ & $82.9(60.5-119.3)$ * & $0.0256^{\mathrm{c}}$ \\
\hline Number of diseases ${ }^{¥}$, median (IQR) & $1.0(0-2.0)$ & $1.5(1.0-3.0)$ & $2(1.0-4.0)$ & $0.1274^{\mathrm{c}}$ \\
\hline Number of medications ${ }^{\#}$, median (IQR) & $1.5(0-3.0)$ & $3.0(1.0-8.0)$ & $3.0(0.5-5.5)$ & $0.3112^{c}$ \\
\hline SPPB summary score, median (IQR) & & $11(11-12)$ & $6(6-7)$ & $0.0002^{\mathrm{d}}$ \\
\hline
\end{tabular}

Abbreviations: BMI, body mass index; HF, high-functioning; IQR, interquartile range; LF, low-functioning; SD, standard deviation; SPPB, short physical performance battery. * $p<0.05$ vs. young group. ${ }^{*}$ includes hypertension, coronary artery disease, prior stroke, peripheral vascular disease, diabetes, chronic obstructive pulmonary disease, and osteoarthritis. " includes prescription and over-the-counter drugs. ${ }^{a}$ Kruskal-Wallis H statistics. ${ }^{b} \chi^{2}$ test. ${ }^{\mathrm{c}}$ One-way ANOVA. ${ }^{\mathrm{d}}$ Mann-Whitney U test.

\subsection{Measurement of Mitochondrial Iron Handling Proteins and Quantification of Iron Isotopes in Muscle Biopsies from Young and Old Participants}

The expression of the two mitochondrial Fe handling proteins mitoferrin and frataxin were measured in muscle samples and evaluated for their association with age and physical performance categories. Mitoferrin levels were significantly higher in muscles of old LF participants compared with young and HF groups ( $p<0.05$; Figure 1A). Conversely, lower protein levels of frataxin were observed in LF older adults compared with young and HF participants ( $p<0.05$; Figure 1B). 
A

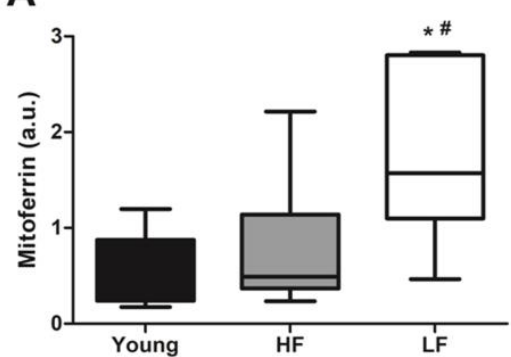

B

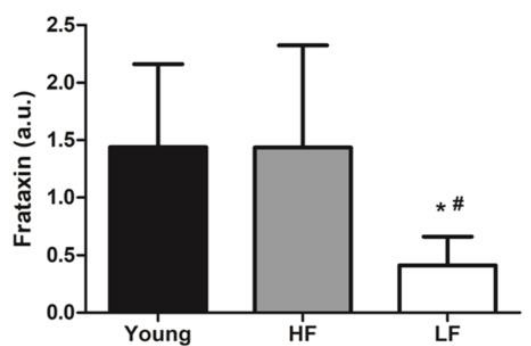

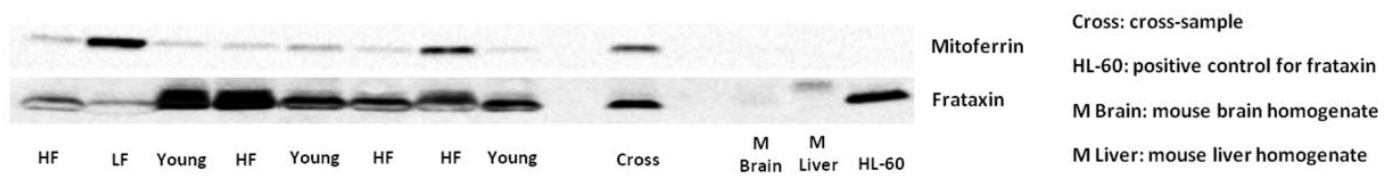

Figure 1. Protein levels of mitoferrin and frataxin in the vastus lateralis muscle of young and old participants. (A) Comparisons of mitoferrin levels by Kruskal-Wallis $\mathrm{H}$ statistics and of (B) frataxin by one-way ANOVA among young participants $(n=11)$ and high- $(\mathrm{HF}, n=16)$ and low-functioning (LF, $n=7$ ) older adults. In (A) box plots represent median values (interquartile ranges), while in (B) bars represent mean values ( \pm standard deviation) for the three experimental groups. Values are expressed in arbitrary units (a.u.) and representative blots are shown for each protein. ${ }^{*} p<0.05$ vs. young group; ${ }^{\#} p<0.05$ vs. HF group.

To gain insights into the Fe status of muscles, we measured the Fe isotope composition across experimental groups. We then evaluated the relationship between $\delta^{56} \mathrm{Fe}$ and $\delta^{57} \mathrm{Fe}$ and between $\delta^{56} \mathrm{Fe}$ and total Fe levels in the whole study population. The ${ }^{56} \mathrm{Fe} /{ }^{54} \mathrm{Fe}$ and ${ }^{57} \mathrm{Fe} /{ }^{54} \mathrm{Fe}$ ratios follow a mass-dependent fractionation relationship $\left(\delta^{56} \mathrm{Fe}\right.$ and $\delta^{57} \mathrm{Fe}$; Figure $\left.2 \mathrm{~B}\right)$ indicating a mass-dependent Fe isotope fractionation. As expected, a value of 1.4848 was found for the slope of the linear trendline which is similar to the theoretical value of $\ln (57 / 54) / \ln (56 / 54) \sim 1.487$ [21]. The reduction of $\mathrm{Fe}^{3+}$ to $\mathrm{Fe}^{2+}$ leads to enrichment of the lighter isotope $\left({ }^{54} \mathrm{Fe}\right)$ in the reduced fraction $[20,21]$ and, according to Equation (1), lower abundance of $\delta^{56} \mathrm{Fe}$ and $\delta^{57} \mathrm{Fe}$ due to lower ${ }^{56} \mathrm{Fe} /{ }^{54} \mathrm{Fe}$ and ${ }^{57} \mathrm{Fe} /{ }^{54} \mathrm{Fe}$ relative to IRM014. As shown in Figure 2A, old LF participants showed lower abundance of $\delta^{56} \mathrm{Fe}$ compared with the young group $(p=0.0461)$. An inverse association was found between total Fe levels and $\delta^{56} \mathrm{Fe}$ abundance in the whole study sample (Figure 2C). The linear correlation detected between more negative $\delta^{56} \mathrm{Fe}$ and higher content of total Fe (Figure 2C) potentially indicates an increasing pool of labile Fe in cells with Fe overload.

A

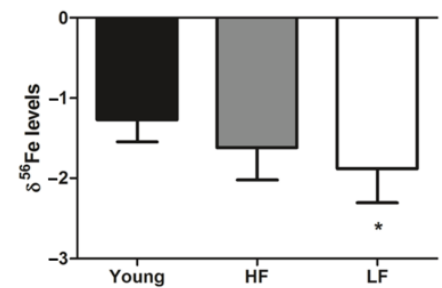

B

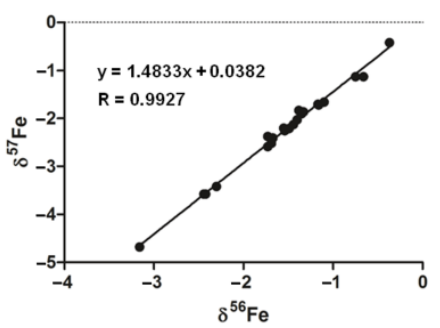

C

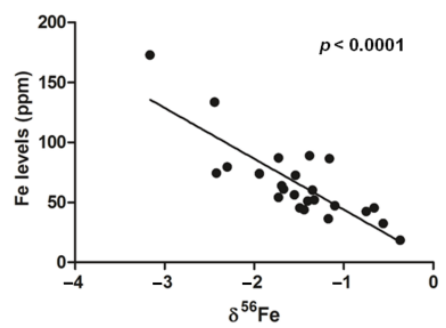

Figure 2. Iron isotope data for the vastus lateralis muscle of young and old participants. (A) Comparison by one-way ANOVA of $\delta^{56} \mathrm{Fe}$ among young participants $(n=11)$ and high- $(\mathrm{HF}, n=16)$ and low-functioning (LF, $n=7$ ) older adults. (B) Linear regression analysis between $\delta^{57} \mathrm{Fe}$ and $\delta^{56} \mathrm{Fe}$ in young and old participants. (C) Relationship between total Fe levels and $\delta^{56} \mathrm{Fe}$ in young and old participants as assessed by Pearson's test. In (A) bars represent mean values ( \pm standard deviation) for the three experimental groups. Values are expressed as ppm Fe. ${ }^{*} p<0.05$ vs. young group. 
3.3. Protein Levels of Selected Markers of Mitochondrial Quality Control and Abundance of the mtDNA $A^{4977}$ Common Deletion

As an indication of mitochondrial dynamics, we derived a fusion index from the ratio between protein levels of the fusion marker optic atrophy 1 and those of the fission factor dynamin-related protein 1 from previously published data in the same population [11]. The fusion index was lower in old versus young participants independent of SPPB scores (Figure 3).

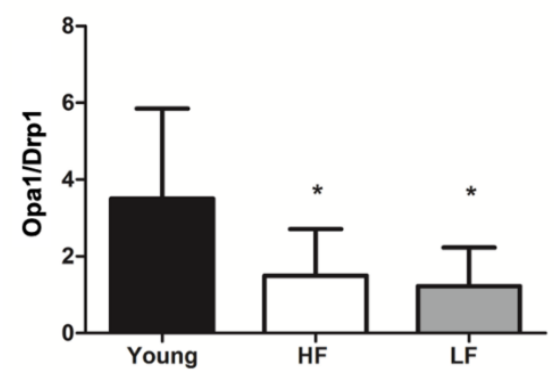

Figure 3. Mitochondrial fusion index in the vastus lateralis muscle of young and old participants. The fusion index was calculated as the ratio between protein levels of the fusion marker optic atrophy 1 (Opa1) and those of the fission factor dynamin-related protein 1 (Drp1). Differences among groups were assessed by one-way ANOVA. Bars represent mean values ( \pm standard deviation) for the three experimental groups. ${ }^{*} p<0.05$ vs. young group $(n=11)$; HF: high-functioning $(n=16)$; LF: low-functioning $(n=7)$.

Selected markers of general (i.e., beclin, LC3B, and p62) and mitochondrial autophagy (i.e., Pink1 and Parkin) were measured in muscle biopsies of all participants and related with age and physical performance. No differences among groups were found for the protein content of beclin $(p=0.5446$, Figure 4A). However, the ratio between the lipidated (II) and the non-lipidated form (I) of LC3B and protein levels of p62, two markers of autophagic flux [64], were significantly lower in old participants independent of SPPB categories ( $p<0.05$, Figure 4B,C).

A

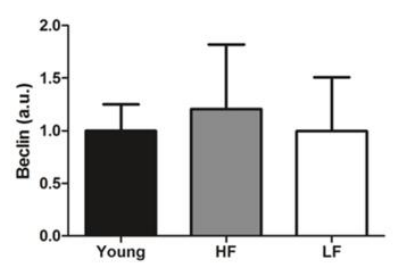

\section{B}

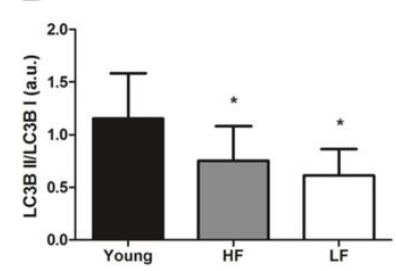

C

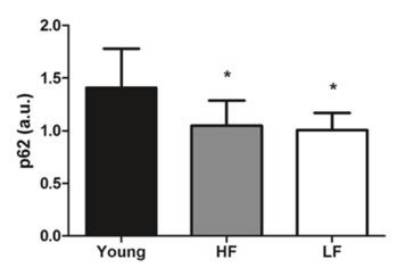

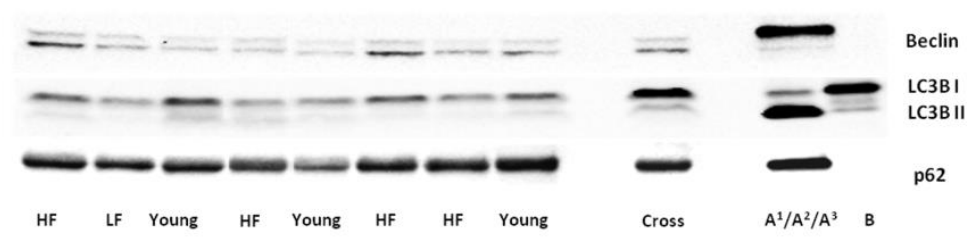

Cross: cross-sample

$A^{1}$ : MDAMB-231-positive control for beclin

$A^{2}$ : HeLa-positive control for LC3B I and LCB II

$A^{3}:$ HL-60-positive control for $p 62$

B: Jurkat positive control for LC3B I and LC3B II

Figure 4. Selected markers of general autophagy in the vastus lateralis muscle of young and old participants. Comparison by one-way ANOVA of (A) protein levels of beclin, (B) ratio between lipidated (II) and non-lipidated (I) microtubule-associated protein 1A/1B-light chain 3 (LC3B), and (C) protein levels of p62 among young participants $(n=11)$ and high- $(\mathrm{HF}, n=16)$ and low-functioning $(\mathrm{LF}, n=7)$ older adults. Bars represent mean values ( \pm standard deviation) for the three experimental groups. Values are expressed in arbitrary units (a.u.) and representative blots are shown for each protein. $* p<0.05$ vs. young group. 
As for the mitophagy markers assayed, higher protein levels of Pink1 were detected in old LF participants compared with young and HF participants $(p<0.05$, Figure 5A). Protein levels of Parkin were instead unvaried among groups ( $p=0.6338$, Figure $5 \mathrm{~B})$.

A

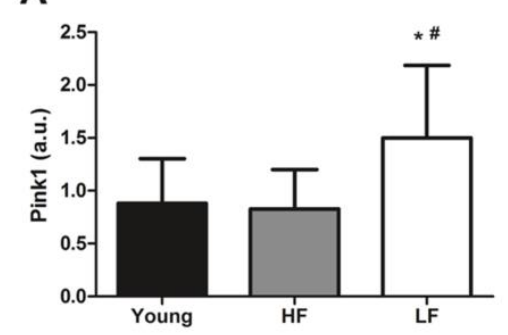

B

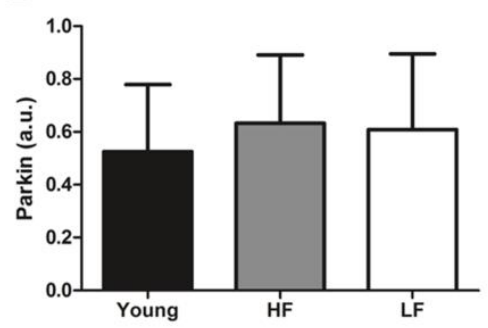

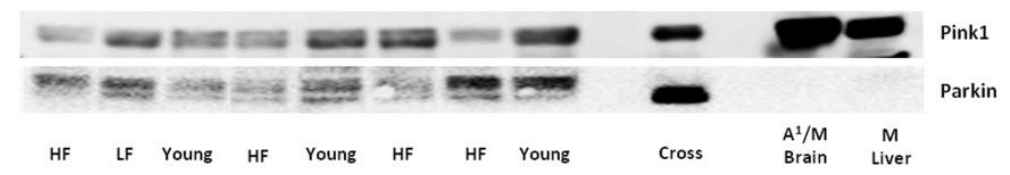

Cross: cross-sample

M Brain: mouse brain homogenate

M Liver: mouse liver homogenate

Figure 5. Protein levels of selected markers of mitophagy in the vastus lateralis muscle of young and old participants. Comparison by one-way ANOVA of (A) phosphatase and tensin homolog-induced kinase 1 (Pink1) and (B) Parkin among young participants $(n=11)$ and high- (HF, $n=16)$ and low-functioning $(\mathrm{LF}, n=7)$ older adults. Bars represent mean values ( \pm standard deviation) for the three experimental groups. Values are expressed in arbitrary units (a.u.) and representative blots are shown for each protein. ${ }^{*} p<0.05$ vs. young group. ${ }^{\#} p<0.05$ vs. HF group.

Finally, the relative abundance of the mtDNA common deletion $\left(\mathrm{mtDNA}^{4977}\right)$ was quantified as a marker of mitochondrial damage. The abundance of such deletion was greater in old participants compared with the young group irrespective of the SPPB category $(p<0.05$, Figure 6$)$.

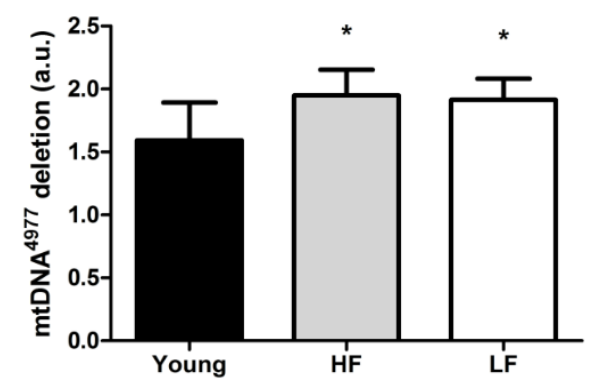

Figure 6. Relative abundance of the mtDNA 4977 deletion in the vastus lateralis muscle of young and old participants. Differences among groups were assessed by one-way ANOVA. Bars represent mean values ( \pm standard deviation) for the three experimental groups. Values are expressed in arbitrary units (a.u.). ${ }^{*} p<0.05$ vs. young group ( $\left.n=11\right)$; HF: high-functioning ( $\left.n=16\right)$; LF: low-functioning $(n=7)$.

\section{Discussion}

The maintenance of skeletal muscle homeostasis relies upon the fine tuning of several processes, including ion balance [65-67]. Indeed, Fe dyshomeostasis is invoked as a factor contributing to age-associated muscle atrophy in rodents and humans through the mediation of oxidative stress [31,32]. A previous study by our group reported higher levels of non-heme Fe in muscles of old rats following hind limb suspension [31]. In rodent muscles, Fe overload was also shown to occur during aging and to be associated with RNA oxidative damage in subsarcolemmal mitochondria [33]. More recently, the relationship between muscular Fe status and age was also investigated in humans [32]. An age-dependent accumulation of non-heme Fe in muscle was found, which was associated with 
lower mtDNA content and greater mtDNA oxidative damage [32]. However, whether non-heme $\mathrm{Fe}$ accumulation in muscle with age is associated with excess labile $\mathrm{Fe}$, as well as its relationship with changes in the expression of proteins involved in mitochondrial Fe handling and quality control, has remained unexplored. Hence, we sought to tackle this aspect of muscle Fe status by investigating whether the Fe isotope composition would be linked to MQC alterations during aging. We also explored whether labile Fe in muscle would be associated with physical performance.

In humans, the relative abundance of Fe isotopes (i.e., isotope fractionation) depends on redox conditions more than on ligand coordination [21], therefore reflecting the redox status of the surrounding milieu. In the scenario, an enrichment in $\mathrm{Fe}^{2+}$ is characterized by lower abundance of $\delta^{56} \mathrm{Fe}$ and ${ }^{57} \mathrm{Fe}$ [21]. Hence, old LF participants, in whom more negative levels of $\delta^{56} \mathrm{Fe}$ were observed, likely had higher levels of $\mathrm{Fe}^{2+}$ in muscle (Figure 2A). This finding, together with the observation of a higher expression of the mitochondrial Fe transporter mitoferrin and a lower content of the mitochondrial $\mathrm{Fe}$ storage protein frataxin in the same participant group (Figure 1A,B), suggests a possible dysregulation of mitochondrial Fe handling [68]. This idea is in keeping with the recent observation of increased intracellular labile Fe in conjunction with upregulation of mitoferrin in a mouse model of frataxin deficiency [68]. Mitoferrin upregulation in muscles of LF older adults might therefore be interpreted as a cell's response to buffer Fe excess. This hypothesis is supported by the lower levels of frataxin detected in the same group, which might be indicative of inability of mitochondria to cope with $\mathrm{Fe}$ overload. This, in turn, would overwhelm the mitochondrial Fe storage capacity with most of the metal remaining unbound. The increased labile Fe content within mitochondria may compromise the organellar integrity via Fenton chemistry, as reflected by the greater abundance of mtDNA ${ }^{4977}$ deletion in old participants (Figure 6).

A shift of mitochondrial dynamics toward fusion is thought to serve as a mechanism to dilute mtDNA damage, including $\mathrm{mtDNA}^{4977}$ deletion, along the network, thereby avoiding its focal accumulation [38]. However, the fusion index, a surrogate indicator of the balance between mitochondrial fusion and fission, was lower in old compared with young participants (Figure 3). This finding could reflect the exhaustion of this compensatory mechanism in the aged muscle. Alternatively, a lower fusion index may indicate a shift toward fission as a response to extensive mitochondrial damage $[38,69]$. This idea is supported by the lower expression of frataxin in old LF participants which might represent an Fe-induced mitochondrial stress response to trigger Pink1/Parkin-dependent mitophagy for the disposal of damaged organelles [70]. However, this was not accompanied by an upregulation of the mitophagic flux, as suggested by decreased LC3B II/I (Figure 4B) and lower p62 levels (Figure 4C) in old participants. Collectively, these findings suggest that the clearance of damaged mitochondria via this route could not be achieved. Indeed, mitochondria primed for mitophagy by Pink1 might not be processed further as a consequence of possible clogging of this degradative pathway, as reflected by unvaried Parkin expression (Figure 5). Based on findings from the present study and those reported previously in the same participant cohort [32], an integrated set of molecular events linking age-related systemic and muscular Fe dyshomeostasis, MQC derangements, and systemic inflammation may be hypothesized as depicted in Figure 7. 


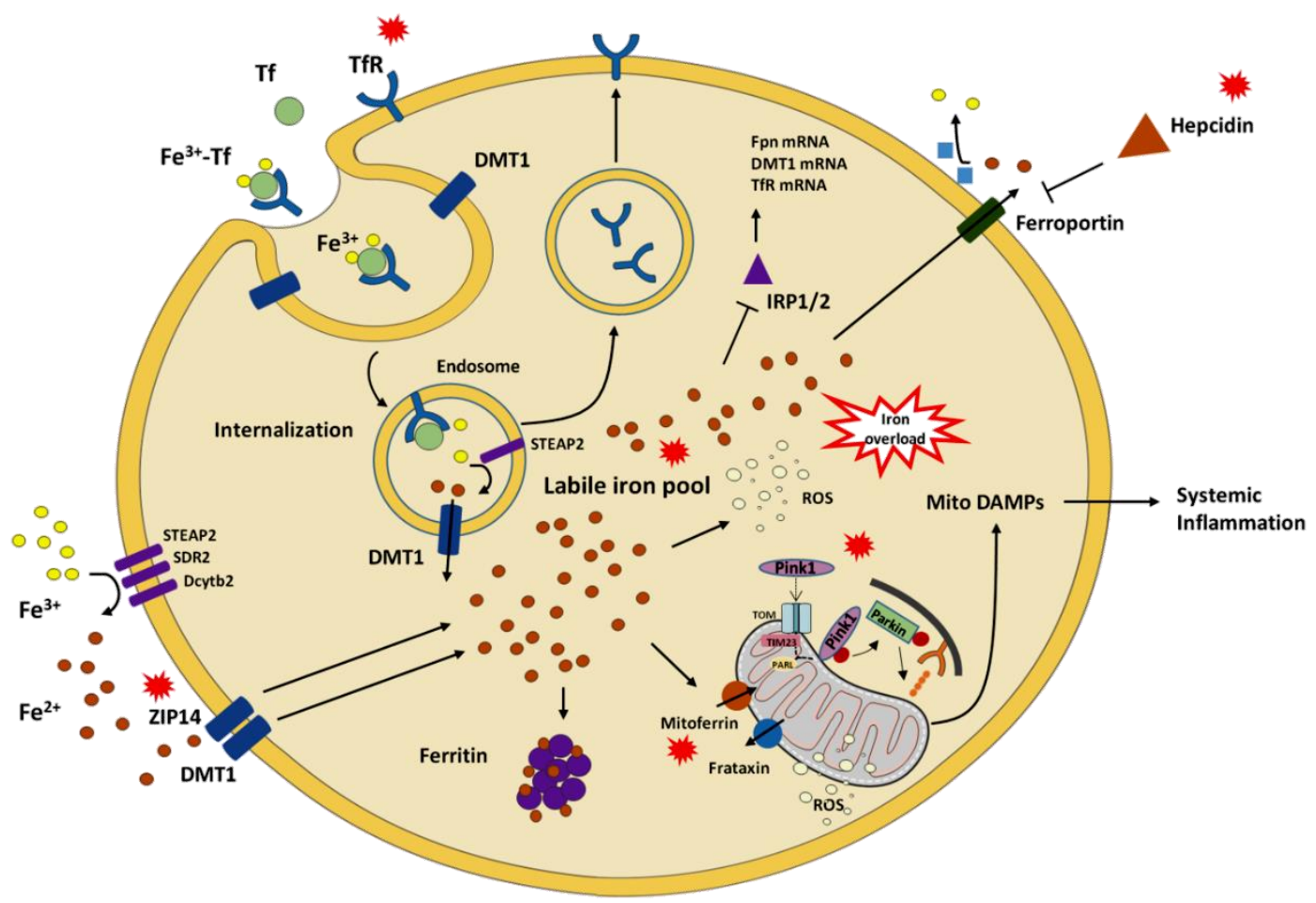

Figure 7. Schematic representation of putative pathways linking age-related systemic and muscular iron dyshomeostasis, derangements in mitochondrial quality control, and systemic inflammation. Red callouts indicate mediators/processes that are mainly dysregulated. Abbreviations: DAMPs, damage-associated molecular patterns; Dcytb2, duodenal cytochrome b2; DMT1, divalent metal transporter 1; Fpn, ferroportin; IRP1/2, iron-responsive element-binding protein 1/2; PARL, presenilin-associated rhomboid-like protein; Pink1, phosphatase and tensin homolog-induced kinase 1 ; ROS, reactive oxygen species; SDR2, stromal cell-derived receptor 2; STEAP2, six-transmembrane epithelial antigen of the prostate 2; Tf, transferrin; TfR, transferrin receptor; TIM23, translocase of inner mitochondrial membrane 23; TOM, translocase of the outer mitochondrial membrane; ZIP14, Zrt-Irt-like protein 14 .

The possibility that Fe mishandling in skeletal muscle might impact physical function through interfering with mitochondrial homeostasis and quality control opens new venues for interventions. Indeed, pharmacological compounds that are already in clinical use to treat a variety of Fe overload diseases (e.g., desferoxamine, deferasirox, deferiprone, salicylaldehyde isonicotinoyl hydrazone, alpha-lipoic acid) may be tested for their ability to scavenge and remove Fe from muscles. Such an approach is currently being explored to treat neurodegenerative diseases characterized by focal Fe accumulation, including Alzheimer's disease, Parkinson's disease, Friedreich's ataxia, and amyotrophic lateral sclerosis [71]. An important issue related to Fe chelation therapy is that presently available compounds are not selective for organs or macromolecular structures. This may substantially limit their use in older adults, in whom iron-deficient anemia is highly prevalent [72]. Calorie restriction (CR) has been shown to mitigate age-associated Fe accumulation in various rodent tissues, including muscle [30]. However, the long-term implementation of this dietary regimen is hampered by feasibility and tolerability issues, especially in frail older adults [73]. This limitation may be overcome through the use of CR mimetics [73], among which resveratrol was found to attenuate the detrimental effects of Fe overload in preclinical models $[74,75]$. Whatever the strategy used, the perspective of preserving physical function in old age via ameliorating muscle Fe handling and mitochondrial homeostasis is worth exploration. In particular, studies are warranted to (1) definitely establish the role of $\mathrm{Fe}$ dysmetabolism in muscle aging and physical function decline, (2) determine the optimal timing for Fe 
scavenging therapies, and (3) identify noninvasively accessible markers of muscle Fe status to monitor the intervention.

\section{Limitations}

To our knowledge, this is the first study to investigate Fe isotope composition and the expression of mitochondrial Fe handling proteins, mitoferrin and frataxin, in human skeletal muscle. However, our work has some limitations that deserve discussion. First of all, the small sample size makes the study exploratory in nature and did not allow analyses to be adjusted for sex or other possible confounders. The limited amount of muscle tissue available narrowed our analyses to selected mediators of pathways pertaining to Fe handling and MQC mechanisms. Indeed, total and phosphorylated protein levels of other mitophagy-related factors, such as TANK-binding kinase 1, optineurin, nuclear dot protein 52, and ubiquitin could not be assessed, which prevented us from achieving a more comprehensive appraisal of the mitophagic process. The cross-sectional design of the study does not allow inferences to be made about the time course of changes of the analyzed factors and cause-effect relationships. For the same reason, no mechanistic hypotheses could be tested regarding the processes leading to Fe dyshomeostasis in muscle and its impact on mitochondrial health. Indeed, our data do not allow establishing whether Fe reduction and isotope fractionation occurred as a result of intracellular redox reactions or during Fe import within the cell. In the latter scenario, since the expression of TfR1 was previously found to be substantially downregulated in muscles of old LF participants [32], Fe isotope fractionation might have occurred during Fe import via divalent metal transporter 1 or Zrt-Irt-like protein 14 . This point warrants further exploration through ad hoc designed investigations. Finally, the study did not include actively exercising participants. Although a physically inactive lifestyle was one of the eligibility criteria, this information was collected through self-report and no objective measure of physical activity was obtained. The lack of this information impeded the appreciation of possible effects of exercise or physical activity on Fe status, mLNA $^{4977}$ abundance, and the expression of MQC mediators in muscle.

Author Contributions: Conceptualization, A.P. and C.L. methodology, A.P. and R.T.M.; formal analysis, A.P., E.M., R.C., T.M.M., and T.W.B.; investigation, A.P., G.K., S.E.W., and S.K.S.; resources, C.L., F.L., and R.B.; data curation, R.T.M.; writing — original draft preparation, A.P., E.M., and S.D.A.; writing-review and editing, C.L., D.A.H., H.J.C.-J., R.C., and R.X.; supervision, E.M. and C.L.; funding acquisition, C.L., F.L., and R.B. All authors have read and agreed to the published version of the manuscript.

Funding: This research was funded by the National Institute on Aging (R01AG17994 and AG028740), Innovative Medicines Initiative-Joint Undertaking (IMI-JU \#115621), Intramural Research Grant from the Università Cattolica del Sacro Cuore (D3.2 2020), and the nonprofit research foundation "Centro Studi Achille e Linda Lorenzon".

Acknowledgments: Figure 7 was drawn using the freely available Servier Medical Art resource (http://www. servier.com/Powerpoint-image-bank).

Conflicts of Interest: The authors declare no conflict of interest. The funders had no role in study design, data collection and analysis, preparation of the manuscript, or decision to publish.

\section{References}

1. Aging Research: Protect Health and Prevent Disease/NIA. Available online: https://www.nia.nih.gov/about/ aging-strategic-directions-research/goal-health-interventions\#c3 (accessed on 14 October 2020).

2. Chang, M.; Cohen-Mansfield, J.; Ferrucci, L.; Leveille, S.; Volpato, S.; De Rekeneire, N.; Guralnik, J.M. Incidence of loss of ability to walk 400 meters in a functionally limited older population. J. Am. Geriatr. Soc. 2004, 52, 2094-2098. [CrossRef]

3. Guralnik, J.M.; Ferrucci, L.; Simonsick, E.M.; Salive, M.E.; Wallace, R.B. Lower-extremity function in persons over the age of 70 years as a predictor of subsequent disability. N. Engl. J. Med. 1995, 332, 556-562. [CrossRef]

4. Pavasini, R.; Guralnik, J.; Brown, J.C.; di Bari, M.; Cesari, M.; Landi, F.; Vaes, B.; Legrand, D.; Verghese, J.; Wang, C.; et al. Short Physical Performance Battery and all-cause mortality: Systematic review and meta-analysis. BMC Med. 2016, 14, 215. [CrossRef] 
5. Fanning, J.; Rejeski, W.J.; Chen, S.H.; Guralnik, J.; Pahor, M.; Miller, M.E. Relationships Between Profiles of Physical Activity and Major Mobility Disability in the LIFE Study. J. Am. Geriatr. Soc. 2020, 68, 1476-1483. [CrossRef]

6. Pahor, M.; Guralnik, J.M.; Anton, S.D.; Ambrosius, W.T.; Blair, S.N.; Church, T.S.; Espeland, M.A.; Fielding, R.A.; Gill, T.M.; Glynn, N.W.; et al. Impact and Lessons From the Lifestyle Interventions and Independence for Elders (LIFE) Clinical Trials of Physical Activity to Prevent Mobility Disability. J. Am. Geriatr. Soc. 2020, 68, 872-881. [CrossRef]

7. Groessl, E.J.; Kaplan, R.M.; Rejeski, W.J.; Katula, J.A.; Glynn, N.W.; King, A.C.; Anton, S.D.; Walkup, M.; Lu, C.J.; Reid, K.; et al. Physical Activity and Performance Impact Long-term Quality of Life in Older Adults at Risk for Major Mobility Disability. Am. J. Prev. Med. 2019, 56, 141-146. [CrossRef]

8. Coen, P.M.; Jubrias, S.A.; Distefano, G.; Amati, F.; Mackey, D.C.; Glynn, N.W.; Manini, T.M.; Wohlgemuth, S.E.; Leeuwenburgh, C.; Cummings, S.R.; et al. Skeletal muscle mitochondrial energetics are associated with maximal aerobic capacity and walking speed in older adults. J. Gerontol. A Biol. Sci. Med. Sci. 2013, 68, 447-455. [CrossRef]

9. Short, K.R.; Bigelow, M.L.; Kahl, J.; Singh, R.; Coenen-Schimke, J.; Raghavakaimal, S.; Nair, K.S. Decline in skeletal muscle mitochondrial function with aging in humans. Proc. Natl. Acad. Sci. USA 2005, 102, 5618-5623. [CrossRef]

10. Short, K.R.; Vittone, J.L.; Bigelow, M.L.; Proctor, D.N.; Rizza, R.A.; Coenen-Schimke, J.M.; Nair, K.S. Impact of aerobic exercise training on age-related changes in insulin sensitivity and muscle oxidative capacity. Diabetes 2003, 52, 1888-1896. [CrossRef]

11. Joseph, A.-M.; Adhihetty, P.J.; Buford, T.W.; Wohlgemuth, S.E.; Lees, H.A.; Nguyen, L.M.-D.; Aranda, J.M.; Sandesara, B.D.; Pahor, M.; Manini, T.M.; et al. The impact of aging on mitochondrial function and biogenesis pathways in skeletal muscle of sedentary high- and low-functioning elderly individuals. Aging Cell 2012, 11, 801-809. [CrossRef]

12. Xu, J.; Marzetti, E.; Seo, A.Y.; Kim, J.-S.; Prolla, T.A.; Leeuwenburgh, C. The emerging role of iron dyshomeostasis in the mitochondrial decay of aging. Mech. Ageing Dev. 2010, 131, 487-493. [CrossRef]

13. Heckerman, D.; Traynor, B.J.; Picca, A.; Calvani, R.; Marzetti, E.; Hernandez, D.; Nalls, M.; Arepali, S.; Ferrucci, L.; Landi, F. Genetic variants associated with physical performance and anthropometry in old age: A genome-wide association study in the ilSIRENTE cohort. Sci. Rep. 2017, 7, 15879. [CrossRef]

14. Timmers, P.R.H.J.; Wilson, J.F.; Joshi, P.K.; Deelen, J. Multivariate genomic scan implicates novel loci and haem metabolism in human ageing. Nat. Commun. 2020, 11, 3570. [CrossRef]

15. Zhang, A.S.; Enns, C.A. Iron homeostasis: Recently identified proteins provide insight into novel control mechanisms. J. Biol. Chem. 2009, 284, 711-715. [CrossRef]

16. Maio, N.; Rouault, T.A. Iron-sulfur cluster biogenesis in mammalian cells: New insights into the molecular mechanisms of cluster delivery. Biochim. Biophys. Acta 2015, 1853, 1493-1512. [CrossRef]

17. Kohgo, Y.; Ikuta, K.; Ohtake, T.; Torimoto, Y.; Kato, J. Body iron metabolism and pathophysiology of iron overload. Int. J. Hematol. 2008, 88, 7-15. [CrossRef]

18. Bresgen, N.; Eckl, P.M. Oxidative stress and the homeodynamics of iron metabolism. Biomolecules 2015, 5, 808-847. [CrossRef]

19. Emerit, J.; Beaumont, C.; Trivin, F. Iron metabolism, free radicals, and oxidative injury. Biomed. Pharmacother. 2001, 55, 333-339. [CrossRef]

20. Walczyk, T.; Von Blanckenburg, F. Deciphering the iron isotope message of the human body. Int. J. Mass Spectrom. 2005, 242, 117-134. [CrossRef]

21. Albarède, F.; Telouk, P.; Lamboux, A.; Jaouen, K.; Balter, V. Isotopic evidence of unaccounted for Fe and Cu erythropoietic pathways. Metallomics 2011, 3, 926-933. [CrossRef]

22. Ganz, T.; Nemeth, E. Hepcidin and disorders of iron metabolism. Annu. Rev. Med. 2011, 62, 347-360. [CrossRef]

23. Nemeth, E.; Tuttle, M.S.; Powelson, J.; Vaughn, M.B.; Donovan, A.; Ward, D.M.; Ganz, T.; Kaplan, J. Hepcidin regulates cellular iron efflux by binding to ferroportin and inducing its internalization. Science 2004, 306, 2090-2093. [CrossRef]

24. Bulteau, A.L.; O’Neill, H.A.; Kennedy, M.C.; Ikeda-Saito, M.; Isaya, G.; Szweda, L.I. Frataxin acts as an iron chaperone protein to modulate mitochondrial aconitase activity. Science 2004, 305, 242-245. [CrossRef] 
25. Napoli, E.; Taroni, F.; Cortopassi, G.A. Frataxin, iron-sulfur clusters, heme, ROS, and aging. Antioxid. Redox Signal. 2006, 8, 506-516. [CrossRef]

26. Boddaert, N.; Sang, K.H.L.Q.; Rötig, A.; Leroy-Willig, A.; Gallet, S.; Brunelle, F.; Sidi, D.; Thalabard, J.C.; Munnich, A.; Cabantchik, Z.I. Selective iron chelation in Friedreich ataxia: Biologic and clinical implications. Blood 2007, 110, 401-408. [CrossRef]

27. Altun, M.; Edström, E.; Spooner, E.; Flores-Moralez, A.; Bergman, E.; Tollet-Egnell, P.; Norstedt, G.; Kessler, B.M.; Ulfhake, B. Iron load and redox stress in skeletal muscle of aged rats. Muscle Nerve 2007, 36, 223-233. [CrossRef]

28. Hofer, T.; Marzetti, E.; Xu, J.; Seo, A.Y.; Gulec, S.; Knutson, M.D.; Leeuwenburgh, C.; Dupont-Versteegden, E.E. Increased iron content and RNA oxidative damage in skeletal muscle with aging and disuse atrophy. Exp. Gerontol. 2008, 43, 563-570. [CrossRef]

29. Jung, S.H.; DeRuisseau, L.R.; Kavazis, A.N.; DeRuisseau, K.C. Plantaris muscle of aged rats demonstrates iron accumulation and altered expression of iron regulation proteins. Exp. Physiol. 2008, 93, 407-414. [CrossRef]

30. Xu, J.; Knutson, M.D.; Carter, C.S.; Leeuwenburgh, C. Iron accumulation with age, oxidative stress and functional decline. PLOS ONE 2008, 3, e2865. [CrossRef]

31. Xu, J.; Hwang, J.C.Y.; Lees, H.A.; Wohlgemuth, S.E.; Knutson, M.D.; Judge, A.R.; Dupont-Versteegden, E.E.; Marzetti, E.; Leeuwenburgh, C. Long-term perturbation of muscle iron homeostasis following hindlimb suspension in old rats is associated with high levels of oxidative stress and impaired recovery from atrophy. Exp. Gerontol. 2012, 47, 100-108. [CrossRef]

32. Picca, A.; Mankowski, R.T.; Kamenov, G.; Anton, S.D.; Manini, T.M.; Buford, T.W.; Saini, S.K.; Calvani, R.; Landi, F.; Bernabei, R.; et al. Advanced Age Is Associated with Iron Dyshomeostasis and Mitochondrial DNA Damage in Human Skeletal Muscle. Cells 2019, 8, 1525. [CrossRef]

33. Seo, A.Y.; Xu, J.; Servais, S.; Hofer, T.; Marzetti, E.; Wohlgemuth, S.E.; Knutson, M.D.; Chung, H.Y.; Leeuwenburgh, C. Mitochondrial iron accumulation with age and functional consequences. Aging Cell 2008, 7, 706-716. [CrossRef]

34. Atamna, H. Heme, iron, and the mitochondrial decay of ageing. Ageing Res. Rev. 2004, 3, 303-318. [CrossRef]

35. Picca, A.; Calvani, R.; Coelho-Junior, H.J.; Landi, F.; Bernabei, R.; Marzetti, E. Inter-Organelle Membrane Contact Sites and Mitochondrial Quality Control during Aging: A Geroscience View. Cells 2020, 9, 598. [CrossRef]

36. Picca, A.; Calvani, R.; Leeuwenburgh, C.; Coelho-Junior, H.J.; Bernabei, R.; Landi, F.; Marzetti, E. Targeting mitochondrial quality control for treating sarcopenia: Lessons from physical exercise. Expert Opin. Ther. Targets 2019, 23, 153-160. [CrossRef]

37. Picca, A.; Mankowski, R.T.; Burman, J.L.; Donisi, L.; Kim, J.-S.; Marzetti, E.; Leeuwenburgh, C. Mitochondrial quality control mechanisms as molecular targets in cardiac ageing. Nat. Rev. Cardiol. 2018, 15, 543-554. [CrossRef]

38. Twig, G.; Hyde, B.; Shirihai, O.S. Mitochondrial fusion, fission and autophagy as a quality control axis: The bioenergetic view. Biochim. Biophys. Acta 2008, 1777, 1092-1097. [CrossRef]

39. Picca, A.; Guerra, F.; Calvani, R.; Bucci, C.; Lo Monaco, M.R.; Bentivoglio, A.R.; Coelho-Júnior, H.J.; Landi, F.; Bernabei, R.; Marzetti, E. Mitochondrial dysfunction and aging: Insights from the analysis of extracellular vesicles. Int. J. Mol. Sci. 2019, 20, 805. [CrossRef]

40. Picca, A.; Guerra, F.; Calvani, R.; Marini, F.; Biancolillo, A.; Landi, G.; Beli, R.; Landi, F.; Bernabei, R.; Bentivoglio, A.; et al. Mitochondrial Signatures in Circulating Extracellular Vesicles of Older Adults with Parkinson's Disease: Results from the EXosomes in PArkiNson's Disease (EXPAND) Study. J. Clin. Med. 2020, 9, 504. [CrossRef]

41. Picca, A.; Beli, R.; Calvani, R.; Coelho-Júnior, H.J.; Landi, F.; Bernabei, R.; Bucci, C.; Guerra, F.; Marzetti, E. Older Adults with Physical Frailty and Sarcopenia Show Increased Levels of Circulating Small Extracellular Vesicles with a Specific Mitochondrial Signature. Cells 2020, 9, 973. [CrossRef]

42. Picca, A.; Guerra, F.; Calvani, R.; Coelho-Junior, H.J.; Bossola, M.; Landi, F.; Bernabei, R.; Bucci, C.; Marzetti, E. Generation and Release of Mitochondrial-Derived Vesicles in Health, Aging and Disease. J. Clin. Med. 2020, 9, 1440. [CrossRef]

43. Picca, A.; Lezza, A.M.S.; Leeuwenburgh, C.; Pesce, V.; Calvani, R.; Landi, F.; Bernabei, R.; Marzetti, E. Fueling Inflamm-Aging through Mitochondrial Dysfunction: Mechanisms and Molecular Targets. Int. J. Mol. Sci. 2017, 18, 933. [CrossRef] 
44. Picca, A.; Lezza, A.M.S.; Leeuwenburgh, C.; Pesce, V.; Calvani, R.; Bossola, M.; Manes-Gravina, E.; Landi, F.; Bernabei, R.; Marzetti, E. Circulating Mitochondrial DNA at the Crossroads of Mitochondrial Dysfunction and Inflammation During Aging and Muscle Wasting Disorders. Rejuvenation Res. 2018, 21, 350-359. [CrossRef]

45. Buford, T.W.; Lott, D.J.; Marzetti, E.; Wohlgemuth, S.E.; Vandenborne, K.; Pahor, M.; Leeuwenburgh, C.; Manini, T.M. Age-related differences in lower extremity tissue compartments and associations with physical function in older adults. Exp. Gerontol. 2012, 47, 38-44. [CrossRef]

46. Marzetti, E.; Lees, H.A.; Manini, T.M.; Buford, T.W.; Aranda, J.M.; Calvani, R.; Capuani, G.; Marsiske, M.; Lott, D.J.; Vandenborne, K.; et al. Skeletal muscle apoptotic signaling predicts thigh muscle volume and gait speed in community-dwelling older persons: An exploratory study. PLoS ONE 2012, 7, e32829. [CrossRef]

47. Marzetti, E.; Landi, F.; Marini, F.; Cesari, M.; Buford, T.W.; Manini, T.M.; Onder, G.; Pahor, M.; Bernabei, R.; Leeuwenburgh, C.; et al. Patterns of circulating inflammatory biomarkers in older persons with varying levels of physical performance: A partial least squares-discriminant analysis approach. Front. Med. 2014, 1, 27. [CrossRef]

48. Guralnik, J.M.; Simonsick, E.M.; Ferrucci, L.; Glynn, R.J.; Berkman, L.F.; Blazer, D.G.; Scherr, P.A.; Wallace, R.B. A short physical performance battery assessing lower extremity function: Association with self-reported disability and prediction of mortality and nursing home admission. J. Gerontol. 1994, 49, M85-M94. [CrossRef]

49. Vasunilashorn, S.; Coppin, A.K.; Patel, K.V.; Lauretani, F.; Ferrucci, L.; Bandinelli, S.; Guralnik, J.M. Use of the Short Physical Performance Battery Score to predict loss of ability to walk 400 meters: Analysis from the InCHIANTI study. J. Gerontol. A Biol. Sci. Med. Sci. 2009, 64, 223-229. [CrossRef]

50. Studenski, S.; Perera, S.; Patel, K.; Rosano, C.; Faulkner, K.; Inzitari, M.; Brach, J.; Chandler, J.; Cawthon, P.; Connor, E.B.; et al. Gait speed and survival in older adults. JAMA 2011, 305, 50-58. [CrossRef]

51. Pahor, M.; Guralnik, J.M.; Ambrosius, W.T.; Blair, S.; Bonds, D.E.; Church, T.S.; Espeland, M.A.; Fielding, R.A.; Gill, T.M.; Groessl, E.J.; et al. LIFE study investigators Effect of structured physical activity on prevention of major mobility disability in older adults: The LIFE study randomized clinical trial. JAMA 2014, 311, 2387-2396. [CrossRef]

52. Marzetti, E.; Cesari, M.; Calvani, R.; Msihid, J.; Tosato, M.; Rodriguez-Mañas, L.; Lattanzio, F.; Cherubini, A.; Bejuit, R.; Di Bari, M.; et al. The "Sarcopenia and Physical fRailty IN older people: Multi-componenT Treatment strategies" (SPRINTT) randomized controlled trial: Case finding, screening and characteristics of eligible participants. Exp. Gerontol. 2018, 113, 48-57. [CrossRef]

53. Maréchal, C.N.; Télouk, P.; Albarède, F. Precise analysis of copper and zinc isotopic compositions by plasma-source mass spectrometry. Chem. Geol. 1999, 156, 251-273. [CrossRef]

54. Craddock, P.R.; Dauphas, N. Iron Isotopic Compositions of Geological Reference Materials and Chondrites. Geostand. Geoanal. Res. 2011, 35, 101-123. [CrossRef]

55. Marzetti, E.; Carter, C.S.; Wohlgemuth, S.E.; Lees, H.A.; Giovannini, S.; Anderson, B.; Quinn, L.S.; Leeuwenburgh, C. Changes in IL-15 expression and death-receptor apoptotic signaling in rat gastrocnemius muscle with aging and life-long calorie restriction. Mech. Ageing Dev. 2009, 130, 272-280. [CrossRef] [PubMed]

56. Saini, S.K.; Li, L.; Peek, C.B.; Kosmac, K.; Polonsky, T.S.; Tian, L.; Criqui, M.H.; Ferrucci, L.; Guralnik, J.M.; Kibbe, M.; et al. Associations of Poly (ADP-Ribose) Polymerase1 abundance in calf skeletal muscle with walking performance in peripheral artery disease. Exp. Gerontol. 2020, 140, 111048. [CrossRef]

57. Picca, A.; Fracasso, F.; Pesce, V.; Cantatore, P.; Joseph, A.-M.; Leeuwenburgh, C.; Gadaleta, M.N.; Lezza, A.M.S. Age- and calorie restriction-related changes in rat brain mitochondrial DNA and TFAM binding. Age 2013, 35, 1607-1620. [CrossRef]

58. Nicassio, L.; Fracasso, F.; Sirago, G.; Musicco, C.; Picca, A.; Marzetti, E.; Calvani, R.; Cantatore, P.; Gadaleta, M.N.; Pesce, V. Dietary supplementation with acetyl-l-carnitine counteracts age-related alterations of mitochondrial biogenesis, dynamics and antioxidant defenses in brain of old rats. Exp. Gerontol. 2017, 98, 99-109. [CrossRef]

59. Chimienti, G.; Picca, A.; Sirago, G.; Fracasso, F.; Calvani, R.; Bernabei, R.; Russo, F.; Carter, C.S.; Leeuwenburgh, C.; Pesce, V.; et al. Increased TFAM binding to mtDNA damage hot spots is associated with mtDNA loss in aged rat heart. Free Radic. Biol. Med. 2018, 124, 447-453. [CrossRef] 
60. Picca, A.; Sirago, G.; Pesce, V.; Lezza, A.M.S.; Calvani, R.; Bossola, M.; Villani, E.R.; Landi, F.; Leeuwenburgh, C.; Bernabei, R.; et al. Administration of enalapril started late in life attenuates hypertrophy and oxidative stress burden, increases mitochondrial mass, and modulates mitochondrial quality control signaling in the rat heart. Biomolecules 2018, 8, 177. [CrossRef]

61. Chimienti, G.; Picca, A.; Fracasso, F.; Marzetti, E.; Calvani, R.; Leeuwenburgh, C.; Russo, F.; Lezza, A.M.S.; Pesce, V. Differences in liver TFAM binding to mtDNA and mtDNA damage between aged and extremely aged rats. Int. J. Mol. Sci. 2019, 20, 2601. [CrossRef]

62. Saini, S.K.; McDermott, M.M.; Picca, A.; Li, L.; Wohlgemuth, S.E.; Kosmac, K.; Peterson, C.A.; Tian, L.; Ferrucci, L.; Guralnik, J.M.; et al. Mitochondrial DNA damage in calf skeletal muscle and walking performance in people with peripheral artery disease. Free Radic. Biol. Med. 2020, 160, 680-689. [CrossRef] [PubMed]

63. Pfaffl, M.W. A new mathematical model for relative quantification in real-time RT-PCR. Nucleic Acids Res. 2001, 29, e45. [CrossRef] [PubMed]

64. Yoshii, S.R.; Mizushima, N. Monitoring and measuring autophagy. Int. J. Mol. Sci. 2017, 18, 1865. [CrossRef]

65. Ravel-Chapuis, A.; Bélanger, G.; Côté, J.; Michel, R.N.; Jasmin, B.J. Misregulation of calcium-handling proteins promotes hyperactivation of calcineurin-NFAT signaling in skeletal muscle of DM1 mice. Hum. Mol. Genet. 2017, 26, 2192-2206. [CrossRef] [PubMed]

66. Wang, G.; Biswas, A.K.; Ma, W.; Kandpal, M.; Coker, C.; Grandgenett, P.M.; Hollingsworth, M.A.; Jain, R.; Tanji, K.; López-Pintado, S.; et al. Metastatic cancers promote cachexia through ZIP14 upregulation in skeletal muscle. Nat. Med. 2018, 24, 770-781. [CrossRef]

67. Summermatter, S.; Bouzan, A.; Pierrel, E.; Melly, S.; Stauffer, D.; Gutzwiller, S.; Nolin, E.; Dornelas, C.; Fryer, C.; Leighton-Davies, J.; et al. Blockade of Metallothioneins 1 and 2 Increases Skeletal Muscle Mass and Strength. Mol. Cell. Biol. 2017, 37, e00305-16. [CrossRef]

68. Martelli, A.; Schmucker, S.; Reutenauer, L.; Mathieu, J.R.R.; Peyssonnaux, C.; Karim, Z.; Puy, H.; Galy, B.; Hentze, M.W.; Puccio, H. Iron Regulatory Protein 1 Sustains Mitochondrial Iron Loading and Function in Frataxin Deficiency. Cell Metab. 2015, 21, 311-323. [CrossRef]

69. Picca, A.; Calvani, R.; Lorenzi, M.; Menghi, A.; Galli, M.; Vitiello, R.; Randisi, F.; Bernabei, R.; Landi, F.; Marzetti, E. Mitochondrial dynamics signaling is shifted toward fusion in muscles of very old hip-fractured patients: Results from the Sarcopenia in HIp FracTure (SHIFT) exploratory study. Exp. Gerontol. 2017, 96, 63-67. [CrossRef]

70. Schiavi, A.; Maglioni, S.; Palikaras, K.; Shaik, A.; Strappazzon, F.; Brinkmann, V.; Torgovnick, A.; Castelein, N.; De Henau, S.; Braeckman, B.P.; et al. Iron-Starvation-Induced Mitophagy Mediates Lifespan Extension upon Mitochondrial Stress in C. elegans. Curr. Biol. 2015, 25, 1810-1822. [CrossRef]

71. Devos, D.; Cabantchik, Z.I.; Moreau, C.; Danel, V.; Mahoney-Sanchez, L.; Bouchaoui, H.; Gouel, F.; Rolland, A.S.; Duce, J.A.; Devedjian, J.C.; et al. Conservative iron chelation for neurodegenerative diseases such as Parkinson's disease and amyotrophic lateral sclerosis. J. Neural Transm. 2020, 127, 189-203. [CrossRef]

72. Romano, A.D.; Paglia, A.; Bellanti, F.; Villani, R.; Sangineto, M.; Vendemiale, G.; Serviddio, G. Molecular aspects and treatment of iron deficiency in the elderly. Int. J. Mol. Sci. 2020, 21, 3821. [CrossRef]

73. Marzetti, E.; Wohlgemuth, S.E.; Anton, S.D.; Bernabei, R.; Carter, C.S.; Leeuwenburgh, C. Cellular Mechanisms of Cardioprotection by Calorie Restriction: State of the Science and Future Perspectives. Clin. Geriatr. Med. 2009, 25, 715-732. [CrossRef]

74. Das, S.K.; Wang, W.; Zhabyeyev, P.; Basu, R.; Mclean, B.; Fan, D.; Parajuli, N.; Desaulniers, J.; Patel, V.B.; Hajjar, R.J.; et al. Iron-overload injury and cardiomyopathy in acquired and genetic models is attenuated by resveratrol therapy. Sci. Rep. 2015, 5, 18132. [CrossRef]

75. Das, S.K.; Desaulniers, J.; Dyck, J.R.B.; Kassiri, Z.; Oudit, G.Y. Resveratrol mediates therapeutic hepatic effects in acquired and genetic murine models of iron-overload. Liver Int. 2016, 36, 246-257. [CrossRef]

Publisher's Note: MDPI stays neutral with regard to jurisdictional claims in published maps and institutional affiliations. 